\title{
Investigating Digital (Dis)engagement of Open Government: Case Study of One Data Indonesia
}

\author{
Agie Nugroho Soegiono \\ Public Administration Department, Faculty of Social and Political Sciences, \\ Universitas Airlangga \\ agienugroho@gmail.com
}

\begin{abstract}
Over the last decade, Indonesia has achieved remarkable progress in promoting transparent and inclusive development through implementing open government principles. This research investigates one of the open government projects in Indonesia- One Data Indonesia (ODI), a one-stop open government data portal that provides accurate, reliable, and interoperable single-reference data for the public to use and redistribute without any limitation. The study aims to highlight the current updates on open data implementation in Indonesia and the challenges that may hinder its application in future. The study is an action research, conducted through the participation of the author in a three-month internship programme at the Executive Office of the President Republic of Indonesia. Data on the portal's engagement was based on Google Analytics. This study finds that there is disengagement in open data implementation, which is reflected by a small percentage of available datasets and an imbalance in user access across Indonesia. This study argues that the disengagement is due to several factors, including irrelevant and uncertain regulatory frameworks, confusion over setting priority goals, inadequate data infrastructure, and limited digital-literate human resource. Despite high investment and expectations from the portal, the benefits and civic engagement it has generated so far remain questionable.
\end{abstract}

Keywords: data management, digital engagement, open data, open government 


\section{INTRODUCTION}

Over the last few years, Indonesia has achieved remarkable progress in embracing open government principles. Indonesia's strong commitment begun in 2011 when Indonesia became one of the co-founding members of Open Government Partnership (OGP). OGP is a multinational commitment that promotes transparent, accountable, and reliable governance by optimising participative and collaborative policy-making process. The follow-up step of this commitment is manifested in the rolling out of Indonesia's pilot project called Satu Data Indonesia (One Data Indonesia). One Data Indonesia - www. data.go.id (hereafter, ODI) is the adaptation of international open data standard that has been implemented around the globe. Inspired by well-established open data portals such as data.gov (the USA) and data.gov.uk (the UK), ODI aims to strengthen evidence-based policy mechanism by embracing data-driven culture (Nugroho, Zuiderwijk, Janssen, \& Jong, 2016).

ODI appears to a one-stop government data portal without restricted access. Since its release in 2014, the portal has been providing open, reliable, and interoperable data for the public to legally use and redistribute at zero-cost (Nugroho \& Hikmat, 2017). ODI is not only aimed at strengthening government accountability and public trust but also to become a solution for data inaccuracy problem in Indonesia by developing a single-reference data system. A single-reference data system will help policymakers create accurate decisions. Within ODI's portal, data are available from a wide range of fields such as education, infrastructure, health, and economics. In order to be published, the minimum requirement for government datum is to achieve at least 3-star rating out of a maximum of 5-star data rating. The 3-star data rating itself requires data to be produced in CSV format. Embracing this standardised specification on data publishing, the government of Indonesia requires every government body at any level to follow the same pattern immediately. During the process of writing this research, there have been more than 2,000 datasets available online from various government institutions across Indonesia. ODI's existence provides ample evidence of the seriousness and political determination of the government in addressing data management issues (Bhunia, 2017).

In order to realize its potential benefits, the open data initiative requires the availability of adequate quality data and data usage management. Global Open Data Index, an international open data measurement project, shows that Indonesia achieved remarkable progress in its open data release in terms of data existence, data digitisation, zero cost structure, and online access in 2015. In comparison with other ASEAN countries, the average score of Indonesia (40) was the second only to Singapore which had a score of 50. Indonesia's impressive rating shows that the country is already performing well with respect to data availability. However, the measurement used in the Global Open Data Index does not capture the aspect of data quality (Stagars, 2016). Optimal data usage will highly depend on data availability and data quality, and therefore, both should be standardized in an open data portal. Data unavailability has the potential to create information gap in policy analysis, leading to inaccuracy, even failures, in policy outcomes.

Another challenge for open data optimization is how to increase the volume and benefits from data usage. Good quality open data will maximise the benefits data users get from their usage. Nevertheless, data availability and quality do not equate to the ability of the citizens to reutilise or reproduce them (Janssen, Charalabidis, \& Zuiderwijk, 2012). This implies that open data portal does not guarantee that citizens will directly gain benefit from the downloadable data. Unless there are efforts to maximise the potential from open data, it will remain untapped. Thus, extracting as many benefits as possible from open data requires more substantial public engagement. 
Given the complexity of open data challenges, this research aims to contribute to open government data debate by providing insights on open data implementation in Indonesia by addressing the following questions: 'what has been the level of public engagement in ODI implementation so far?' and 'what obstacles has public engagement faced during ODI implementation?'. This research has two primary goals. First, this research will highlight the current condition of ODI, particularly with respect to data availability and user access across Indonesia. Second, this study will try to identify the obstacles that have hampered the government strategy to widen and promote open data principles in Indonesia.

\section{METHODS}

This study used a mixed methodology approach technique, collating both qualitative and quantitative data. Qualitative findings were used to analyze the progress in ODI implementation from 2014-2017. Context analysis included legal formal, political interest, business process, and data management. Quantitative data were used to highlight the degree to which the use of ODI's portal is widespread in Indonesia. The numeric data were also utilized to capture users' characteristics of the ODI's portal.

Data collection was based on action research and desk research. The author conducted action research by participating in a three-month internship programme held at the Executive Office of the President of the Republic of Indonesia (Kantor Staf Presiden Republik Indonesia, hereby KSP), particularly in OneData Indonesia's secretariat. The author served as a policy analyst charged with the task of monitoring and analyzing the progress of open data initiative in Indonesia. During the internship, the author was able to participate as well as observe several meetings that took the form of institutional visits, open data readiness assessments, and public events such as datadriven journalism competition and public data forum. In-depth interviews were also conducted during these agendas with relevant open data stakeholders who hailed from ministries, national government bodies, local authorities, and NGOs.

Upon completing the internship programme, the author organized desk research that was aimed at collecting data and information available online from research journals, news, regulations, and reports on the open data initiative across the globe. Quantitative data were obtained online by observing ODI's portal (www.data.go.id and big data visualization using Google Analytics. Data gained from Google Analytics were restricted since January 2017 only. In addition, data obtained from Google Analytics were unable to cover personal characteristics of ODI's users such as social-economic background, educational background, and download activities.

\section{FINDINGS AND DISCUSSION}

To answer the research questions, the discussion below is divided into three literature reviews sections. The first section discusses the contribution of open government principles toward creating a more transparent environment by publishing open data. This part specifically discusses term 'data' and the urgency of data digitization. The second and third parts describe benefits of open data in terms of business process, social and political aspects followed by essential components that are necessary to realize digital engagement. The conceptual framework discussed in literature review is used in reviewing data findings with respect to data availability and user access to ODI portal.

\section{Open Government Principles and Their Correlation with Open Data}

Open government is the idea of disclosing government information to stimulate broader economic opportunities by involving non-government sectors and civil society (Malamud, 2010). By opening 


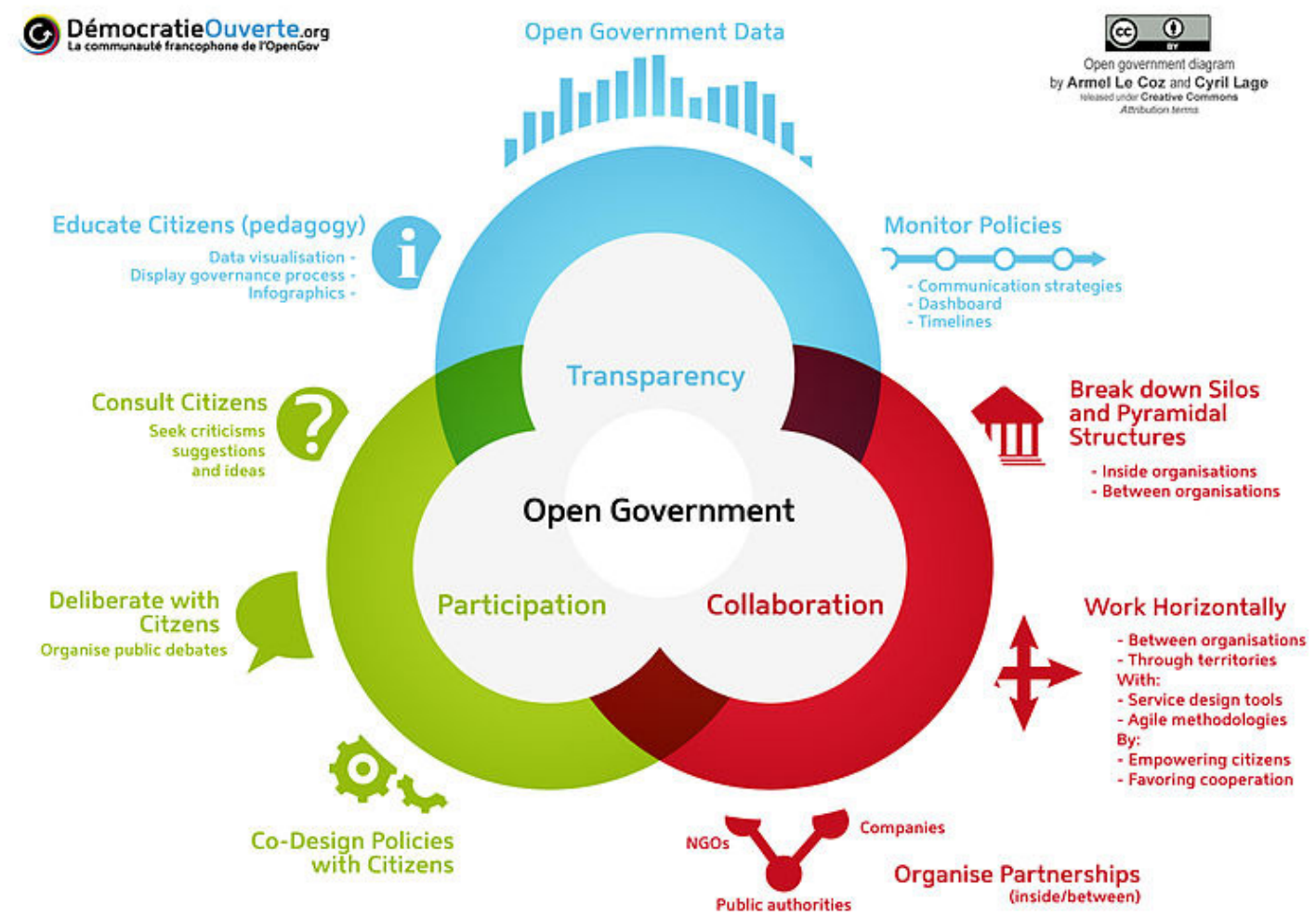

Figure 1: Open Government Diagram

Source: The General Assembly of the Collective Open Government in Paris, (2015)

access to the public, the government increases the opportunity to encourage and effect a participatory and collaborative policy process. With the public having more chances to speak to their government, open government creates conditions for policy oversight to be more objective and inclusive, leading to more accurate and better-quality decisions. Although there is a wide range of open government projects applied around the world, this section only focuses on the open data initiative.

Studies on open government generally are in agreement that without public information disclosure act open government projects are difficult to implement (McDermott, 2010; Bates, 2014; Stagars, 2016). The act generally mandates government institutions, including ministries, agencies, and local authorities, to provide public access to government information. Public information disclosure also guarantees the rights that enable the citizen to gain and request information at the particular institution. This mandate becomes the core as well as the legal foundation for open government frameworks in the country. Public information disclosure not only becomes a vital component of better transparency and accountability in the government but also serves as an opportunity that ensures higher public participation and access to the policy process. Policy by the people stimulates the 'wisdom of the crowd,' allowing engaged citizens to participate and collaborate with their government in various ways. Consequently, public administration becomes stronger due to the diversity of expertise and new opportunities for innovation through cooperation with non-profit organisations and businesses (Veit \& Huntgeburth, 2014). In addition, substantial civic participation and involvement increase public trust in the incumbents (Gant \& Turner-Lee, 2011). Thus, the essence of public information disclosure act is evident and crucial to providing a legal basis for open government initiatives. 
In general, open government embraces three interconnected principles; transparency, participation, and collaboration. These three principles are cited in most of the open government studies in the US, which received strong support from the Obama administration (Noveck, 2010). For more clarity, Rogers and Lindsey (2012) categorize the three open government principles into civic society's roles. Transparency provides civic access, participation boosts civic engagement, while collaboration, the final stage, realizes civic involvement (Rogers \& Lindsey, 2012). The General Assembly of the collective Open Government in Paris illustrates these three principles as figure 1 .

Transparency is the primary step in implementing the culture of openness in government. Without efforts to unlock the public sharing of government information, participative and collaborative governance is hard to achieve. However, the level and format of information that can or cannot be shared with the public remain debatable among open government scholars. A study in the US argues that open government can be divided into several steps of maturity in which the first two stages are called 'initial conditions' and 'data transparency' (Lee \& Hwak, 2012 , p. 496). Initial conditions refers to the situation where the government is concerned mainly with disseminating information using a one-way and static communication website. The shared information consists of non-indepth information on particular government institution. Lee and Kwak do not define 'open data' until the second state, which is called 'data transparency'; at which stage, the government is willing to release rawer information/material. Publishing data instead of information is where transparency enters a higher level of public disclosure. According to various scholars, data contain more in-depth transparency content where their usage is more functional and machine-readable (Manyika et al., 2013; Misuraca \& Viscusi, 2014; Nam, 2015). For that reason, this study deems it necessary to highlight open data coverage and why their features are essential for further usage.

Open data, according to many international organisations are defined as data that are openly available for everyone to obtain, reuse, and redistribute freely (Manyika et al., 2013; Ubaldi, 2013; World Bank Group, 2015). In connection with the internet of things era, well-known dictionaries associate the 'data' keyword with computerisation or digitisation. Such definition implies that the term 'data' is associated with digital format. However, this does not necessarily mean that digital data are always open. On the other hand, the production of open data can also be in a non-digital format as long as the data are easy to access by the public. This explains why even governments with low technological advancement might still be able to publish their data conventionally. However, in line with of technological advancement, data availability should be published in digital format. In terms of access, today's 'published' means online. When available online, open data become easily obtainable or downloadable because digitisation of data increases the interoperability aspect of the data.

Online data dissemination creates a betterintegrated mechanism for data management. Concerning their format, open data are not only in the forms of numeric or statistical format, but also include maps, sensor readings, social media posts, photos, and videos (Jetzek, Avital, \& Bjørn-andersen, 2014). Provided in a wide variety of formats makes open data management a challenging task for data providers, especially essential features that enable multi interaction between data providers and data users. However, publishing online data is possible given that open data has an open license. This license allows and legally guarantees data sharing and distribution without any restriction (Rogers \& Lindsey, 2012). The easier the access to data, the more people are able to access them, and the more significant benefits of their usage.

However, sustaining both open government and open data projects requires 
interactive platforms. Janssen, Charalabidis, and Zuiderwijk (2012) argue that government is deemed insufficient if it is solely responsible for providing data to the public without expecting and responding to feedback. Thus, to ascertain that both data providers and data users' interests are met, there is need to take into consideration data supply and demand. The idea to create citizen-sourcing environment is an advanced step of open government movement, participation, and collaboration. By using citizen-centered paradigm, the role of the government is reduced from serving as gatekeepers of information to facilitators of information. When it comes to data and information optimization, citizens are allowed to maximize published data as well as information without any restricted access that might influence policymaking process depending on national agenda (Veit \& Huntgeburth, 2014). This can be seen in today's start-up phenomena whereby the sharing economy has disrupted big players in businesses and the way government improves public services and benefits to civil society in general. Therefore, to allow any room for feedback and improvement, data management should embrace participation and collaboration values.

\section{The Prospectus Benefits of Open Data}

Open data play an important role in the success of open government initiatives. To maximize transparency, participation, and collaboration, the production and publication of open data should be in raw format. Tim Berners Lee, the founder of World Wide Web Foundation, categorizes five different levels of standardized open data, which he calls the 5-star scheme ("5 $\square$ Open Data," n.d.). These five distinct levels are utilized as a measurement to determine the level of interoperability of a datum's quality to be integrated into the web. A 1-star datum is released in a proprietary format, such as PDF, that might cause users to work non-automatically. Meanwhile, a 5-star datum is accessible online, integrated into
URIs, consisting links for users to identify the resources in the data. Lee suggests that open government data should fulfill at least the 3-star rating, in a CSV format that is inclusive enough to be reused in many kinds of computer software. The higher the rating, the more interoperable the data. By increasing data interoperability, data users have the opportunity to use data in many ways that may reveal insights and create innovations. Therefore, the benefits of open data depend on their format.

In his book, Stagars (2016) divides open data benefits into three different sectors; economic, business process, and socialpolitical. Economically, open data have high potential to enhance a region's competitiveness. By maximizing the usage of open data, a government can stimulate innovations which in turn impact on economic growth. McKinsey\&Company estimates that open data might boost annual economic potentials by $\$ 3$ trillion (Manyika et al., 2013). The reason for that potential lies in the data liquidness of data. Liquidness of data potentially detects excellent amounts of real-time and historical information in searching patterns and anomalies, which reveal possibilities for new convenient products and services. The data-driven culture drives the business sector to engage in targeted marketing, which is more efficient and effective. The prospects are high considering the fact that everyone today can become a data producer as well as a user thanks to increasing importance of smart devices and internet users.

The second benefit from open data lies in the business process. The ability of open data to integrated and interoperable in multisystem makes it possible for data providers to find redundancy and inaccuracy between datasets. The potential advantage also relies on open data project in Indonesia. ODI (One Data Indonesia) agenda, which aims to reduce miscalculation of analysis due to the existence of redundant data (Unit Kerja Presiden Bidang Pengawasan dan Pengendalian Pembangunan, 2014). With multi-connected systems, open data enables government bodies to maximize 
administrative process and fasten data sharing. Another benefit is the existence of a validation mechanism, which is easier to do when data sources merge into an integrated system. These benefits allow the government to strengthen its quality control that in turn is very crucial for policy-making process.

The last but not least, is the benefit for the social and political sector. Open data promote inclusive development. The non-restricted access for everyone enables both data experts and non-data experts to monitor and evaluate government activities. Public access enhances transparency and accountability to a new level where everyone can be involved in decision support as well as monitoring and evaluation. Feedback features on open data portals might also create knowledge bank development where government and non-government can strengthen their knowledge capacity to be not only more informed but also make evidencebased policy actions.

\section{Digital Engagement for Open Data Usage}

As mentioned above, even though open data are not always in digital format, this research only focuses on online open government data usage. The potential of open data is higher when data management is done through computerization process with the help of relevant ICTs (Nugroho et al., 2016; Veit \& Huntgeburth, 2014). ICT usage for open data digitization proposes not only improvement in data management features, but also in the facilitation of collaborative works between government and non-government sectors. However, the digitizing process cannot bolster multiplayer works automatically. To do so, data stakeholders need to stimulate public engagement to increase people's awareness of open data benefits. Since an open data portal only provides data in digital format, engagement should be executed in digital acts as well. This section highlights digital engagement framework in an open data optimization.

When it comes to digitization, literature on civic engagement recognizes the contribution of digital literacy to achieve proficiency (Helsper \& Eynon, 2013). A wide range of ICT usage has stimulated researchers to understand the different types of digital literacy components such as computer skills and internet use. These core competencies have transferred significant changes in human activities, making them more efficient, convenient, transparent, and responsive. While ICT usage has led to significant changes in human activities and behaviors, society's expectations of public services have also increased. Thus, creating an ideal digital environment in society requires digital skill enhancement among service providers and service users.

According to Helsper and Eynon (2013), digital skills are essential competencies that enable ICT user to engage in digital activities for subsequent functions. Similar to other activities, the involvement of participants in digitized events require access to inclusive resources. Inclusive resources include economic, cultural, social, and personal factors that contribute significantly to improving digital engagement. For example, broad access to free internet services and internet devices in a particular area can stimulate an individual's digital skills since there are no financial costs incurred. Digital skills comprise technical, critical, social, creative skillsets such as managing websites, building platforms, and understanding contents that lead to the maximum use of digital platforms. The increase in the skillset of internet users contributes toward the creation of an inclusive digital environment that is essential to achieve digital engagement (see figure 2).

The great disparity of digital resources might offer significant benefits to members of society who can transform regular activities into digital ones. On the other hand, many digital features are also complex to measure. The broad areas covered by the digital initiative, such as business and politics often create bias in individual's perception of digital activity. For example, a public figure who frequently shares his/her thoughts through social media 


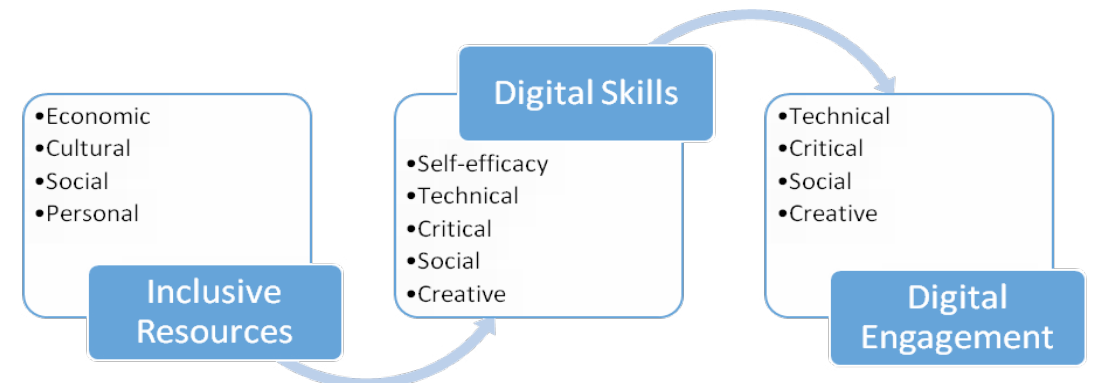

Figure 2: Digital inclusion conceptual framework that relates to skills and engagement Source: (Helsper \& Eynon, 2013)

might be interpreted differently by the public as merely social interaction or driven by political motives. In contrast, although the public might respond to an official's online message, it is not easy to determine whether a digital activity that users do such as comment, like, or share can be categorized as befitting an appropriate civic participation. Such innumerable digitized activities complicate efforts of researchers to determine the exact skills needed for digital projects.

In regards to open data optimization, data users are expected to not only be equipped with digital literacy but also data literacy (Fotopoulou \& Couldry, 2015). Although no research mentions the fixed skills necessary to conduct open data initiative, data literacy skills are often mentioned in open data literature. Data management skills can be technical, critical, social, and creative. Technical data skills include data discovery, data visualization, and data conversion (Fotopoulou \& Couldry, 2015; Koltay, 2015). Another essential skill is critical data thinking, which relates to systematic thinking on data management. For instance, what mechanism is used to produce data? what are the limitations of particular data? Does published data have any inconsistency? Social aspect in data literacy concerns the types of data that are needed to realize a social project. Finally, creative aspect of data literacy relates to using available data to develop applications.

To conclude, it is indispensable for data producers to focus not only on data availability but also data usage. In order to realize broad public engagement in data utilization, and deriving advantages from the open data initiative, there is need to strengthen and equip the public with necessary digital skills.

\section{Current Picture of ODI's Engagement}

\section{Data Availability Status}

As discussed above, ODI is expected to become a single national data management system that will be implemented at national and local level. ODI also follows open data international standardization with respect to guidelines and guidelines on production and publication mechanisms of data by government agencies. During the research period, the author identified more than 2,000 datasets from various institutions across the country in the ODI platform. However, based on contents of table 1 , it is evident that the number of participating government institutions remains far from expectations. Thus, most government agencies have yet to participate in the project.

Nonetheless, given the large number of disconnected institutions, data management based on ODI's portal is likely to experience digital disengagement. Moreover, disengagement in data management is prevalent in all types of institutions at various levels of government. For example, regional government register low score on the percentage of participating institutions. According to open data principles, obtaining a single-datareference requires adequate data management that calls integration, interconnectedness, and interoperability across agencies from regional 
Table 1: the number of participating government institutions in ODI.

Types of Institutions $\quad$ Number of Institutions Available Total Number of in One Data Indonesia's Portal Institutions in Indonesia

Ministries

Government Agencies

Regional Governments

State-owned Enterprises

Source: www.data.go.id (November 2017).

\section{5}

9

4

1
34

30

548

118 to national level. Hence, with only a small percentage of regional governments integrated into the portal, promoting data usage at the national level might be a challenging task to achieve. In any case, low participation of government institutions in ODI might lead some authorities to question the quality of national data. This is because without the participation of lower-level government agencies, tracing datasets from the national government lower tier levels is difficult. For example, data on the number of public schools is not easy to trace to a particular local education department. Therefore, current data availability in ODI's portal might not be accurate and accountable nor represent adequate data quality.

\section{The Condition of User Access}

This section highlights the characteristics of data users who have visited the ODI's portal based on Google Analytics (see figure 3 and appendix 1 below). In 2017, nearly 720, 000 different users across the globe accessed the portal 5.3 million times. The majority of users (96.8\%) came from Indonesia, followed by United States $(0.56 \%)$, Singapore $(0.37 \%)$, and Malaysia $(0.30 \%)$. A user averagely spent two minutes and 5.17 sessions per visit, with only a small percentage experiencing a bounce rate $(3.33 \%)$. Figure 3 shows that the user of the portal is active during the visit. Of the 720,000 visitors, more than $30 \%$ were returning visitors, and accessed the portal more than once. Although the percentage of returning visitors does not represent the satisfaction rate of the site visit, the figure might be interpreted to mean that the portal affords some visitors value which attracts them to pay return visits to use its features.
To get an in-depth portrait of the distribution of the portal use, appendix 1 highlights the characteristics of ODI's visitors by region in Indonesia. In general, most visitors of ODI's portal are based in big cities, with cities in Java island dominating the top 10 ranking. Only four cities outside Java, inter alia Denpasar, Medan, Makassar, and Pontianak. In other words, access to portal services is still largely limited to people from big cities in Indonesia. Another striking finding is the zero rate in goal conversation rate, goal completions and goal value, which underscore the fact that access to the portal and its features are free of charge and without restrictions.

Although Google Analytics enables us to see the whole picture of portal usage based on real-time analysis, its limitation lies in its failure to disclose details of users' characteristics such as social-economic background, occupation, education level, and purpose of visiting the portal. This means that despite a large number of site visits, we cannot use the findings to differentiate users by sector (government and non-government) since details on users' profile are absent. Secondly, the table does not portray the full picture of access to the portal from all parts of the country. Finally, it is not possible to explore data to determine the way users make use of the data obtained from portal.

By adopting Helsper \& Eynon's digital inclusion framework, this research argues that the small percentage of regional government data in ODI is attributable to the lack of inclusive resources among government institutions. In fact, the acknowledgment of the Ministry of Home Affairs regarding the nonexistence of documentation and information management 

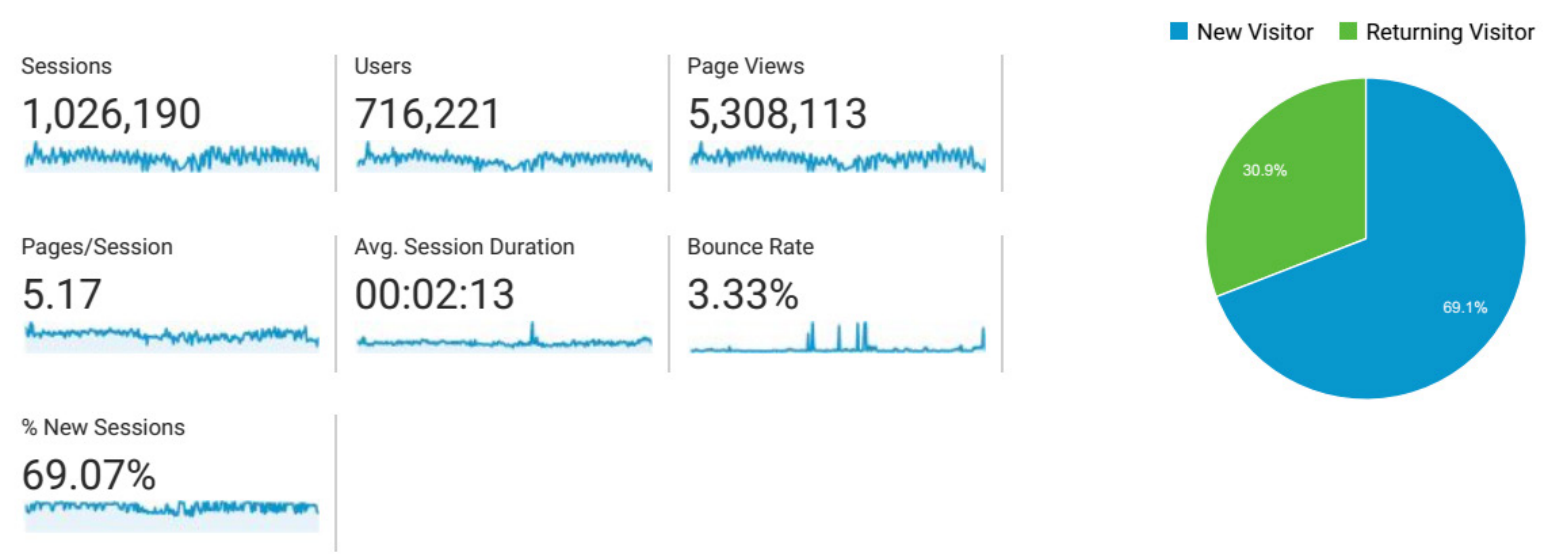

Figure 3 Audience Overview of ODI's Portal data.go.id in 2017

Source: Google Analytics (2017)

officers (PPID) across Indonesia strengthens the argument. As mandated by Indonesia's public information disclosure in 2008, government institutions at all levels are required to appoint a PPID, who is a special officer responsible for collecting, providing, classifying, filing, and documenting governmental information. However, by November 2017, only 111 out of 548 regional governments had appointed their PPIDs. The nonexistence of PPIDs at the local level attests to the poor state of data management across the country as the position bears fundamental responsibilities that are vital to achieving ODI's goals.

With respect to digital capability, a blueprint titled "Satu Data untuk Pembangunan Berkelanjutan" (One Data for Sustainable Development), reveals several cases that highlight the problem of inadequate data skills among government officers (Unit Kerja Presiden Bidang Pengawasan dan Pengendalian Pembangunan, 2014). Inadequate data skills run the gamut, including data awareness, basic data knowledge, producing data, classifying, and publishing techniques. Although this research has not been able to find numeric information about data literacy of public officials, the cases in the report provide clues as to the nature of the formidable task that is required to realize a comprehensive, continuous, and sustainable plan to conduct data-driven culture in government bodies.
Based on the above discussion, it is not difficult to identify indicators and signs of disengagement in ODI's implementation. Three years since its release in 2014, ODI has shown little progress in integrating government organisations. The slow progress is illustrated by the small number of connected institutions to ODI's portal as well as many cases of digital illiteracy among government officials. To that end, optimising ODI requires widening multiorganisational connectedness right from the local to national level. Considering the fact that the majority of government institutions in Indonesia is still unconnected, shades doubt on the accuracy of currently available government data. This does not however mean that disconnected government institutions cannot implement standardised data management. That said, even if that were to be possible, maintaining open data principles in ODI's portal would be challenging under conditions where institutions do not base their data management activities on the same principles and standard.

\section{Obstacles in Implementing ODI in Indonesia}

The previous section has highlighted the current condition of ODI's implementation across Indonesia. Although this research does not have all the evidence needed to give a whole picture of the efficacy of the program, this 
section tries to illustrate some of the obstacles that have prevented ODI initiative to achieve its full potential.

\section{Irrelevant and Nonexistent Regulatory Framework}

Despite the existence of the public information disclosure act which is expected to promote openness culture in Indonesia, this research contends that regulation is no longer be relevant with respect to open data principles and advancement in ICT. The Indonesia public information disclosure act does not explicitly define data. The definition of data is still based on stipulations of Law No. $16 / 1997$ on Statistics as 'data are information in the form of numbers relating to the special characteristics of a population'. Compared to today's open data principles, this definition is no longer appropriate/superfluous. Moreover, in the public information disclosure act, information is defined in general terms, rather than specifically. In any case, 'information' alone is insufficient to enforce government institutions to publish data in accordance with open data principles.

Based on the perspective of this research, there is a big difference between data and information whereby the latter has been subjected to interpretation by official hence unlikely to be analyzed deeper compared to the former that is still in 'raw' form. Thus, data are raw materials that contain a higher level of transparency, accountability, and interoperability. Such raw material is more machine-readable rather than human-readable, which makes them have higher potential for further analysis, development and utilization.

The lack clarity between data and information has caused misconceptions in regional governments that are willing to participate in the initiative. Based on the author's observation during a visit to Pontianak and Mojokerto city governments, local officials could not distinguish the difference between the data and information. On being asked for data, local officials often provided data in the form of news and government reports. These items were one-way, static and non-in-depth information, which could not be analyzed further. However, what local governments did was not a mistake in accordance with the regulatory framework. The regulation only mandates government institutions to provide relevant information without any details on its format, material, and context.

Another regulatory problem is the unavailability of e-Government regulation. Despite the rapid growth in ICT usage, the government of Indonesia is still unable to release the regulation that thoroughly guides ICT-based innovations across the country. The absence of regulation of ICT led to uncoordinated ICT-based implementation for those local governments that initially implemented certain advanced technology. Considering the high dependency of the initiative on ICT, the non-existence of ICT regulation has to a large extent curtailed open data implementation. To conclude, regulations on data and e-Government play an important role in serving as a guide toward quickening the pace of optimizing open data implementation in Indonesia. In other words, without proper regulatory framework, ODI initiative has the potential to experience disengagement in its implementation due to misconception, misunderstanding, and poor coordination. Irrelevant and non-existent regulation strong influence operational procedures of the open data initiative.

\section{Indirective Political Motive}

Unlike other open data initiatives in many parts of the world, the choice to use 'one data' instead of 'open data' in Indonesia is a unique case. According to an interview with ODI Director, 'one data' is more politically acceptable than 'open data'. Despite its promising benefits that have been applied in other countries, the terminology of 'open' is interpreted by many public sector leaders in government institutions as risky. The specter of realizing data to the public without 
any restrictions is for incumbent officials tantamount to opening their performance to unfettered and unfiltered scrutiny of the public eye. Therefore, the 'open' term harbors political insecurity for some government institutions. On the other hand, the change from 'open data' to 'one data' is for open data enthusiasts, considered an indirect political choice that is bound to cause disengagement between data stakeholders in its implementation.

Indonesia has been facing the problem of poor data management in the policymaking process, which is attributable to data unavailability, data inaccuracy, data inconsistency, and lack of valid data (Unit Kerja Presiden Bidang Pengawasan dan Pengendalian Pembangunan, 2014). For policymakers, accurate and reliable data are crucial ingredients of an effective decision making process. Therefore, the strategy adopted by ODI stakeholders to support the need for a one-single-data reference that can be accessed across government stakeholders, is very much in that line of thinking. However, the demand for might lead to confusion among government officials. This is because the demand for onesingle-data-reference and open data format application are not the same.

The need for a one-single-data-reference is supposed to support the conduct of activities such as data forum, data validation, data monitoring and evaluation, and data feedback. Most activities focus on obtaining the most accurate, one-data reference through check and re-check mechanism, data forum consulting, and feedback from data stakeholders from various organizations. On the other hand, promoting the production of data based on an open format activities focuses on such activities such as digitizing process, improving application programming interface, and website integration. Thus, the two demands will lead to different activities that might create confusion in determining how best to organize data among data stakeholders. In the end, the confusion will lead to data disengagement of stakeholders in deciding their priority goals.

\section{Inadequate ICT Infrastructure and Digital- Literate Human Resources}

Based on the Indonesia's association of internet service provider - APJII (2014) sources, only 88 of 250 million population $(30 \%)$ had access to internet. Access to internet connection is highly dependent on infrastructure development, which currently is an even with the eastern part lagging the Western part of the country. This leads to a huge disparity among internet users across the archipelago. According to APJII (2014), $60 \%$ of active internet users in Indonesia lived on Java island, followed by Sumatra island (21\%), Sulawesi (9\%), and Borneo (5\%), and the eastern islands such as Maluku, Nusa Tenggara, and Papua for the rest (5\%) (APJII, 2014). The difference in infrastructure and internet access inevitably impact on human resource capacity. Consequently in parts of the country where infrastructure is poorly compounded by lack of quality human resources, makes operationalizing the open data initiative difficult to implement. Even though no research has come up with a clear definition of the term 'digital capability', this study argues that there is a significant digital divide among government agencies. Consequently, the initiative of the central government to produce one-single -data reference as well as an integrated open data portal might be difficult to achieve.

Another argument is that open data requires highly complex skills to manage, which can be developed through proper education and training. These skills include computing, statistical, programming, data analytics, and other skills necessary to optimize data usage. In other words, open data usage might not work for everyone which unfortunately is contrary to the promise of inclusiveness that open government touts. Open data will be useless materials as long as the user is incapable of utilizing them. Therefore, the implementation of ODI is likely to face the problem of limited human resources to operationalize open data principles appropriately. 
In order to tackle these problems, policies should be directed toward accelerating infrastructure development, especially ICT infrastructure, as well as provision of adequate training and education to enhance human resource capabilities. However, the recommended actions will require substantial expenditures. For example, besides spending a high amount of money on ICT infrastructure development, proper data management necessitates sustainable financing for its maintenance. This was confirmed by Benison (2016), who revealed that the production of good quality of open data entails a substantial budget in the long run, which comes in four categories namely setup and technical cost, administrative and governance, skills development and community engagement, and sustainability cost. In other words, the government open data project requires a lot of investment and extensive involvement of multi-stakeholders, while benefits have not been identified clearly.

\section{CONCLUSION}

Since becoming a member of the OGP, Indonesia has shown its eagerness to adopt many open government best practices around the globe. The interest and commitment of the government of Indonesia, is reflected in its open data campaign. In many parts of the world, open data campaign aims to promote transparent, accountable, clean government, and enhancing public trust and sustainable development. However, open data initiative in Indonesia has its own distinctive goals that include addressing inaccurate information issues due to the absence of single-reference, accurate, and reliable data.

Data are crucial elements of the policy process. Data are the core that underpins policymakers' knowledge in understanding developments in any field. Without accurate, reliable, and precise data, expected policyoutcomes might be difficult to achieve. The same applies to the condition of unavailable data that will eventually lead to information gap in the decision-making process. Thus, it is undeniable that Indonesia urgently needs one data. One data appears as an open data initiative in the form of one-stop government data portal and has been running for the last four years.

Nonetheless, research findings who that the performance of Indonesia open data initiative is showing potential signs of disengagement between data producers and data users. The disengagement is largely as a result of the relatively small number of participating government bodies, the unequal user access distribution, and the unexploited data usage potential. This study argues that the disengagement is due to several factors, including irrelevant and uncertain regulatory framework, confusion of priority goals whether to strengthen data openness or to create a single-reference data system; and disparity in ICT infrastructure and inadequate human resources.

Open data will be useless materials if no one is able to extract their potential benefits. Considering the current condition of ODI implementation, this research is pessimistic that benefits of ODI's portal will be obtained within the short term. However, there is always room for improvement. Therefore, there is need for strategic and sustainable efforts in dealing with existing legal, institutional, and data literacy obstacles. First, there is need for a new regulation that should oblige government bodies to disseminate their data to the portal. Since there is currently no relevant legal basis for open data management, the existence of such a regulation on open data will be pivotal. Alternatively, issuing a regulation that obliges adoption of e-government will foster government agencies to provide data through the open data portal. Equally important is the need for unique data and information definition to serve as guidance to information officers hence will reduce confusion. At the institutional level, government bodies should be required to establish data management units. Data production is a large process that requires a lot 
of human, technology, and financial resources. To that end, achieving a single data reference, based on a standardised mechanism requires agreement among government agencies if the problem of inaccurate data issues due to data redundancy or data unavailability is to be minimized even eradicated. This can be achieved through data forum that involves data stakeholders that are convened periodically. Data forum might also be a strategic mechanism where determining the priorities of data stakeholders whether it should be to create a single-reference data first or enhancing the quality of available data. Last but not least, increasing digital literacy can only be achieved if public participation and collaboration with many sectors, is forged and facilitated. Achieving that can take the form of public hearings, hackathons, or research on data management issues.

\section{REFERENCES}

$5 \square$ Open Data. (n.d.). Retrieved from http://5stardata.info/en/

Asosiasi Penyelenggara Jasa Internet Indonesia - APJII. (2014). Profil Pengguna Internet Indonesia 2014. Apjii. Retrieved from https://www.apjii.or.id/survei2016

Benison, M. (2016). Open Data - How Much Does It Cost? Retrieved from https:// govex.jhu.edu/wiki/open-data-howmuch-does-it-cost/

Bhunia, P. (2017). Brief Look at Open Government Data in 6ASEAN Countries. Retrieved from http://opengovasia. com/articles/7336-brief-look-at-opengovernment-data-in-6-asean-countries

Fotopoulou, A., \& Couldry, N. (2015). Telling the Story of the Stories: Online Content Curation and Digital Engagement. Information Communication and Society, 18(2), 235-249. https://doi.org/10.1080/ 1369118X.2014.952317

Gant, J., \& Turner-Lee, N. (2011). Government transparency: Six Strategies. Communications.
Helsper, E. J., \& Eynon, R. (2013). Distinct Skill Pathways to Digital Engagement. European Journal of Communication, 28(6), 696-713. https://doi. org/10.1177/0267323113499113

Janssen, M., Charalabidis, Y., \& Zuiderwijk, A. (2012). Benefits, Adoption Barriers and Myths of Open Data and Open Government. Information Systems Management, 29(4), 258-268. https:// doi.org/10.1080/10580530.2012.716740

Jetzek, T., Avital, M., \& Bjørn-andersen, N. (2014). Generating Sustainable Value from Open Data. IFIP International Federation for Information Processing, 62-82.

Koltay, T. (2015). Data literacy : in Search of a Name and Identity. Journal of Documentation, 71(2), 401-415. https:// doi.org/10.1108/JD-02-2014-0026

Lee, G., \& Hwak, H. Y. (2012). An Open Government Maturity Model for Social Media-based Public Engagement. Government Information Quarterly, 29(4), 492-503. https://doi.org/10.1016/j. giq. 2012.06.001

Malamud, C. (2010). By the People. In D. Lathrop \& L. Ruma (Eds.), Open Government: Collaboration, Transparency, and Participation in Practice. O'Reilly.

Manyika, J., Chui, M., Groves, P., Farrell, D., Kuiken, S. Van, \& Doshi, E. A. (2013). Open Data: Unlocking Innovation and Performance with Liquid Information.

Misuraca, G., \& Viscusi, G. (2014). Is Open Data Enough? International Journal of Electronic Government Research, 10(1), 18-34. https://doi.org/10.4018/ ijegr.2014010102

Nam, T. (2015). Challenges and Concerns of Open Government: ACase of Government 3.0 in Korea. Social Science Computer Review, 33(5), 556-570. https://doi. org/10.1177/0894439314560848

Noveck, B. S. (2010). The Single Point of Failure. In D. Lathrop \& L. Ruma (Eds.), 
Open Government: Collaboration, Transparency, and Participation in Practice. O'Reilly.

Nugroho, R. P., Zuiderwijk, A., Janssen, M., \& Jong, M. de. (2016). Transforming Government: People, Process, and Policy. Transforming Government: People, Process and Policy - A Comparison of National Open Data Policies: Lessons Learned, 10(2), 190-195. https://doi. org/10.1108/TG-03-2016-0016

Nugroho, Y., \& Hikmat, A. (2017). An Insider's View of e-Governance under Jokowi: Political Promise or Technocratic Vision? In E. Jurriëns \& R. Tapsell (Eds.), Digital Indonesia Connectivity and Divergence (p. 304). ISEAS - Yusof Ishak Institute. Retrieved from https://bookshop.iseas. edu.sg/publication/2245

Unit Kerja Presiden Bidang Pengawasan dan Pengendalian Pembangunan. (2014). Cetak Biru Satu Data untuk Pembangunan Berkelanjutan. Jakarta. Retrieved from http://perpustakaan.bappenas. go.id/lontar/file?file=digital/165679-[ Konten_]-Konten D1674.pdf

Rogers, P., \& Lindsey, T. D. (2012). Principles of open Government data. CRB Shoty Subjects: Open Government Series, (August), 2. Retrieved from https:// opengovdata.org/
Stagars, M. (2016). Open data in Southeast Asia: Towards Economic Prosperity, Government Transparency, and Citizen Participation in ASEAN. Palgrave Macmillan. https://doi.org/10.1007/9783-319-32170-7

The General Assembly of the Collective Open Government in Paris. (2015). La Démocratie Ouverte, ou "Open Government." Retrieved from http://www.participationet-democratie.fr/en/node/1994

Ubaldi, B. (2013). Open Government Data: Towards Empirical Analysis of Open Government Data Initiatives. OECD Working Papers on Public Governance No. 22, (22).

Veit, D., \& Huntgeburth, J. (2014). Foundations of Digital Government: Leading and Managing in the Digital Era. Springer. https://doi.org/10.1007/978-3-642-38511-7

World Bank Group. (2015). Open Data for Sustainable Development, 33. Retrieved from http://pubdocs.worldbank.org/ en/999161440616941994/Open-Datafor-Sustainable-Development.pdf 
Agie Nugroho Soegiono — Investigating Digital (Dis)engagement of Open Government.....

\section{APPENDIX 1}

The distribution of ODI user from Indonesia in 2017

\begin{tabular}{lccccccccc}
\hline \multicolumn{1}{c}{ City } & Sessions & $\begin{array}{c}\text { \% New } \\
\text { Sessions }\end{array}$ & $\begin{array}{c}\text { New } \\
\text { Users }\end{array}$ & $\begin{array}{c}\text { Bounce } \\
\text { Rate }\end{array}$ & $\begin{array}{c}\text { Pages/ } \\
\text { Session }\end{array}$ & $\begin{array}{c}\text { Average } \\
\text { Session } \\
\text { Duration }\end{array}$ & $\begin{array}{c}\text { Goal } \\
\text { Conversion } \\
\text { Rate }\end{array}$ & $\begin{array}{c}\text { Goal } \\
\text { Completions }\end{array}$ & $\begin{array}{c}\text { Goal } \\
\text { Value }\end{array}$ \\
\hline Jakarta & 4,763 & $51.14 \%$ & 2,436 & $7.68 \%$ & 2.94 & $00: 02: 15$ & $0.00 \%$ & 0 & US $\$ 0.00$ \\
Surabaya & 1,100 & $78.55 \%$ & 864 & $9.73 \%$ & 3.83 & $00: 02: 46$ & $0.00 \%$ & 0 & US $\$ 0.00$ \\
Denpasar & 766 & $80.81 \%$ & 619 & $5.09 \%$ & 3.56 & $00: 01: 58$ & $0.00 \%$ & 0 & US $\$ 0.00$ \\
Bandung & 537 & $70.20 \%$ & 377 & $8.57 \%$ & 5.32 & $00: 04: 04$ & $0.00 \%$ & 0 & US $\$ 0.00$ \\
Medan & 426 & $80.05 \%$ & 341 & $11.03 \%$ & 3.45 & $00: 02: 09$ & $0.00 \%$ & 0 & US $\$ 0.00$ \\
Makasar & 413 & $81.36 \%$ & 336 & $8.23 \%$ & 3.6 & $00: 02: 30$ & $0.00 \%$ & 0 & US $\$ 0.00$ \\
Depok & 318 & $63.52 \%$ & 202 & $15.09 \%$ & 4.47 & $00: 04: 39$ & $0.00 \%$ & 0 & US $\$ 0.00$ \\
Semarang & 241 & $65.56 \%$ & 158 & $16.60 \%$ & 6.67 & $00: 03: 07$ & $0.00 \%$ & 0 & US $\$ 0.00$ \\
Pontianak & 164 & $64.63 \%$ & 106 & $11.59 \%$ & 6.51 & $00: 04: 01$ & $0.00 \%$ & 0 & US $\$ 0.00$ \\
Yogyakarta & 156 & $73.72 \%$ & 115 & $9.62 \%$ & 4.47 & $00: 02: 42$ & $0.00 \%$ & 0 & US $\$ 0.00$ \\
\hline
\end{tabular}

Source: Google Analytics (2017) 